\section{Reply to J.-E. Bibault et al, B. Tombal, and C. Cattrini et al}

We would like to thank Bibault et al, ${ }^{1}$ Tombal, ${ }^{2}$ and Cattrini et $\mathrm{al}^{3}$ for their insightful comments on the STOMP (Surveillance or Metastasis-Directed Therapy for Oligometastatic Prostate Cancer Recurrence) trial. ${ }^{4}$ We would like to take this opportunity to address some of the important issues raised.

The three letters argue that androgen-deprivation therapy (ADT) is the standard of care for patients included in the STOMP trial. Our patients had a biochemical recurrence after maximal local therapy, with up to three nodal or metastatic lesions on choline positron emission tomography-computed tomography (PET-CT); a majority had negative conventional imaging. Both Tombal $^{2}$ and Cattrini et $\mathrm{al}^{3}$ argue that the TOAD (Timing of Androgen Deprivation) trial reported in 2016 clearly indicates that ADT is the standard of care and that our control arm with surveillance is unjustified. ${ }^{5}$ Firstly, we want to indicate that our trial was designed in 2011 and recruited the last patient in August 2015, well before the TOAD trial was reported. Important to highlight is the fact that a majority of patients in the TOAD trial experienced relapse after primary radiotherapy, in contrast to patients in the STOMP trial $(>60 \% \vee 24 \%) .{ }^{4,5}$ Several studies have already indicated that the pattern of recurrence is different, and we expect that a majority of patients in the TOAD trial experienced a local relapse. ${ }^{6,7}$ Local recurrences were excluded in the STOMP trial. Additionally, the TOAD trial was not able to demonstrate an overall survival benefit in the prostate-specific antigen relapse group, with an unadjusted hazard ratio for overall survival of 0.58 (95\% CI, 0.30 to 1.12 ), nor was there a prostate cancer-specific survival benefit. ${ }^{5}$ As Brand and Parker stated, "taken together with the lack of statistical significance, it is clear that any difference in overall survival is consistent with the null hypothesis and the play of chance." $8(\mathrm{p522})$ Secondly, the 2017 European Urology Association guidelines still include the following statement on ADT in this setting: "Based on the lack of definitive efficacy and the undoubtedly associated significant side effects, not all patients with recurrence after primary curative therapy should receive standard HT." ${ }^{9(p 72)}$ The recommendation in 2011 and in 2017 was and still is: "Do not routinely offer ADT to asymptomatic men with biochemical recurrence" $9(\mathrm{p} 76)$ (grade A recommendation, level 3 evidence). Consequently, we and others ${ }^{8-10}$ are not convinced that ADT is the only standard of care for patients such as those included in the STOMP trial. In the three letters, the relevance of our primary end point of ADT-free survival is questioned. We agree with the authors that this is not a hard end point, but we disagree that it is unethical or subjective or biased. The start of ADT was prespecified at trial design (local progression, progression to $>$ three metastases, or symptomatic progression), and as such, it was not subjective or biased. We believe that at conception of the trial and in agreement with current European Urology Association guidelines, surveillance is still a valid and ethical option in this specific patient group. ${ }^{8-10}$

Cattrini et $\mathrm{al}^{3}$ argue that ADT plus docetaxel or abiraterone is standard of care for oligorecurrent prostate cancer, based on the results of STAMPEDE (Systemic Therapy in Advancing or Metastatic Prostate Cancer: Evaluation of Drug Efficacy). ${ }^{11}$ Patients in both STAMPEDE and CHAARTED (Chemohormonal Therapy Versus Androgen Ablation Randomized Trial for Extensive Disease in Prostate Cancer) are not comparable to those in STOMP. ${ }^{11}$ A recent update of the CHAARTED trial indicated that patients with low-volume disease do not benefit from ADT plus docetaxel. ${ }^{12}$ Consequently, we believe that the suggestion by Cattrini et al is not supported by the trial data or the guidelines.

$\mathrm{Tombal}^{2}$ argues that the sensitivity and specificity of choline and even prostate-specific membrane antigen PET-CT are insufficient to guide metastasis-directed treatment (MDT). First of all, we agree that PET-CT misses microscopic disease and that repeated MDT courses might be warranted; nevertheless, with this approach, no grade $\geq 2$ toxicity was reported, nor was there a decline in quality of life, in contrast to studies providing immediate ADT. ${ }^{5}$ Therefore, we were surprised that both Tombal and Cattrini et $\mathrm{al}^{3}$ believe PET-CT imaging is good enough to determine whether to start immediate systemic therapy. Secondly, the question of which sensitivity/specificity cutoff should be used for any novel imaging before it is used in a clinical trial remains. For example, repeated magnetic resonance imaging-based stereotactic radiosurgery is becoming standard of care for brain metastases in favor of whole-brain radiotherapy plus stereotactic radiosurgery, despite $50 \%$ of patients experiencing relapse within the brain within 1 year. ${ }^{13}$ Although the sensitivity of magnetic resonance imaging in the setting of brain metastases is far from perfect, the strategy of repeated MDT is appealing because of less toxicity and comparable survival. ${ }^{13}$ Consequently, we believe that modern PET tracers are at least ready for inclusion in prostate cancer clinical trials.

\section{Piet Ost and Dries Reynders}

Ghent University, Ghent, Belgium

\section{Karel Decaestecker}

Ghent University Hospital, Ghent, Belgium

Valérie Fonteyne

Ghent University, Ghent, Belgium

\section{Nicolaas Lumen}

Ghent University Hospital, Ghent, Belgium

Bieke Lambert

Ghent University and AZ Maria-Middelares Ghent, Ghent, Belgium

\section{Louke Delrue}

Ghent University Hospital, Ghent, Belgium

Gert De Meerleer

Ghent University, Ghent, Belgium 


\section{ACKNOWLEDGMENT}

The STOMP trial was funded by Kom op tegen kanker, a Belgian nonprofit organization. The funders did not have access to the raw data and had no role in study design, data collection, data analysis, data interpretation, or writing of the report. P.O. is a Senior Clinical Investigator of the Research Foundation-Flanders (Belgium).

\section{AUTHORS' DISCLOSURES OF POTENTIAL CONFLICTS OF INTEREST}

Disclosures provided by the authors are available with this article at jco.org.

\section{REFERENCES}

1. Bibault J-E, Blanchard P: Treating metastatic prostate cancer with local therapies: Is it still wishful thinking? J Clin Oncol 36:2348-2349, 2018

2. Tombal B: Metastasis-targeted therapy: Ready for phase III? J Clin Oncol 36: 2349-2350, 2018

3. Cattrini $\mathrm{C}$, Zanardi $E$, Boccardo F: Androgen-deprivation therapy is more than palliation in oligometastatic prostate cancer. J Clin Oncol 36:2350, 2018

4. Ost P, Reynders D, Decaestecker K, et al: Surveillance or metastasisdirected therapy for oligometastatic prostate cancer recurrence: A prospective, randomized, multicenter phase II trial. J Clin Oncol 36:446-453, 2018

5. Duchesne GM, Woo HH, Bassett JK, et al: Timing of androgen-deprivation therapy in patients with prostate cancer with a rising PSA (TROG 03.06 and VCOG PR 01-03 [TOAD]): A randomised, multicentre, non-blinded, phase 3 trial. Lancet Oncol 17:727-737, 2016
6. Parker WP, Davis BJ, Park SS, et al: Identification of site-specific recurrence following primary radiation therapy for prostate cancer using $\mathrm{C}-11$ choline positron emission tomography/computed tomography: A nomogram for predicting extrapelvic disease. Eur Urol 71:340-348, 2017

7. De Bruycker A, Lambert B, Claeys T, et al: Prevalence and prognosis of lowvolume, oligorecurrent, hormone-sensitive prostate cancer amenable to lesion ablative therapy. BJU Int 120:815-821, 2017

8. Brand $D$, Parker C: Management of men with prostate-specific antigen failure after prostate radiotherapy: The case against early androgen deprivation. Eur Urol [epub ahead of print on January 3, 2018]

9. Cornford P, Bellmunt J, Bolla M, et al: EAU Guidelines. Edn. presented at the EAU Annual Congress London, 2017

10. van den Bergh RC, van Casteren NJ, van den Broeck T, et al: Role of hormonal treatment in prostate cancer patients with nonmetastatic disease recurrence after local curative treatment: A systematic review. Eur Urol 69:802-820, 2016

11. Vale $C L$, Burdett $S$, Rydzewska LHM, et al: Addition of docetaxel or bisphosphonates to standard of care in men with localised or metastatic, hormonesensitive prostate cancer: A systematic review and meta-analyses of aggregate data. Lancet Oncol 17:243-256, 2016

12. Kyriakopoulos $\mathrm{CE}$, Chen $\mathrm{YH}$, Carducci $\mathrm{MA}$, et al: Chemohormonal therapy in metastatic hormone-sensitive prostate cancer: Long-term survival analysis of the randomized phase III E3805 CHAARTED trial. J Clin Oncol [epub ahead of print on January 31, 2018]

13. Brown PD, Jaeckle $K$, Ballman KV, et al: Effect of radiosurgery alone vs radiosurgery with whole brain radiation therapy on cognitive function in patients with 1 to 3 brain metastases: A randomized clinical trial. JAMA 316:401-409, 2016

DOI: https://doi.org/10.1200/JCO.2018.78.2144; published at jco.org on June 1, 2018 


\section{AUTHORS' DISCLOSURES OF POTENTIAL CONFLICTS OF INTEREST}

Reply to J.-E. Bibault et al, B. Tombal, and C. Cattrini et al

The following represents disclosure information provided by authors of this manuscript. All relationships are considered compensated. Relationships are self-held unless noted. I = Immediate Family Member, Inst = My Institution. Relationships may not relate to the subject matter of this manuscript. For more information about ASCO's conflict of interest policy, please refer to www.asco.org/rwc or ascopubs.org/jco/site/ifc.

\section{Piet Ost}

Consulting or Advisory Role: Ferring Pharmaceuticals (Inst), Bayer HealthCare Pharmaceuticals (Inst)

Research Funding: Merck (Inst)

Dries Reynders

No relationship to disclose

\section{Karel Decaestecker}

Consulting or Advisory Role: Intuitive Surgical (Inst), Medtronic (Inst) Travel, Accommodations, Expenses: Ipsen, Astellas Pharma, Ferring Pharmaceuticals

\section{Valérie Fonteyne}

No relationship to disclose

\section{Nicolaas Lumen}

Honoraria: Astellas Pharma

Consulting or Advisory Role: Janssen Oncology (Inst)

Speakers' Bureau: Janssen Oncology

Research Funding: Janssen Oncology (Inst)

Travel, Accommodations, Expenses: Bayer HealthCare Pharmaceuticals

\section{Bieke Lambert}

Consulting or Advisory Role: AbbVie

Louke Delrue

No relationship to disclose

Gert De Meerleer

No relationship to disclose 